\title{
Association between Social Anxiety Symptoms and Suicidal Risk in College Students
}

\author{
Sang-Hun Lee, MD, Hyun-JuYang, MD, PhD, Na Ri Kang, MD, Young-Eun Jung, MD, PhD, \\ Joon Hyuk Park, MD, PhD, Moon-Doo Kim, MD, PhD, Young-Sook Kwak, MD, PhD \\ Department of Psychiatry, Jeju National University School of Medicine, Jeju, Korea
}

\begin{abstract}
Background: Social anxiety and suicide are serious common problems in college students. However, there are few studies on the relationship between social anxiety symptoms and suicidal risk. Therefore, we evaluated the association between social anxiety symptoms and suicidal risk in college students.

Methods: A total of 579 college students were recruited for a college-based cross-sectional survey in the Jeju area. The participants completed a questionnaire gathering sociodemographic information; they also completed the Korean Social Avoidance and Distress Scale (SADS) to assess social anxiety symptoms and the Center for Epidemiologic Studies Depression Scale (CES-D) to assess depressive symptoms. To obtain information regarding suicidal risk, we administered the Korean version of the Suicide module of the Mini International Neuropsychiatric Interview (M.I.N.I.). Results: The prevalence of higher levels of social anxiety symptoms among college students was $28.0 \%(n=162)$. A higher level of social anxiety symptoms resulted in a 2.10-times higher suicidal risk after adjusting for depression in college students ( $95 \%$ confidence interval, $1.05-4.23 ; p=0.037$ ).

Conclusion: Based on the results of this study, social anxiety symptoms should be managed and controlled to prevent suicidality in Korean college students.
\end{abstract}

Keywords Social anxiety symptoms; Suicidal risk; Depression; College students

\section{INTRODUCTION}

Social anxiety disorder is a serious mental illness with high prevalence, which can lead to a significant loss of psychosocial function. The lifetime prevalence of social anxiety disorder was approximately $13 \%$ in the United States in 2012, which was the second largest number among anxiety disorders in the United States [1] and that in Korea in 2016 was $1.6 \%$, which means it was the third most common anxiety disorder in Korea [2]. Social anxiety disorder is characterized by prominent and persistent fear of social situations, such as being exposed to strangers or closely observed by other persons $[3,4]$. People with social anxiety symptoms are anxious about most social situations and try to avoid them, which may eventually lead to severe disability in many areas of life $[5,6]$.

Suicide is a serious problem for young adults, such as college students. In 2017, the rate of suicide per 100,000 people in the ages of 20-29 years in South Korea was 16.4. It was $44.8 \%$ of the cause of death in people in their 20s. This shows that suicide is the most common cause of death for people in their 20s [7]. About $90 \%$ of those who died from suicide had psychiatric illnesses such as depression, anxiety disorders and substance use disorders [8]. This high association between suicide and psychiatric illness suggests that assessment and treatment of psychiatric illness is essential for college students showing suicide-related behaviors.

Received September 9, 2019, Revised September 26, 2019, Accepted October 1, 2019

Correspondence: Young-Eun Jung, MD, PhD

Department of Psychiatry, Jeju National University School of Medicine, 15 Aran 13-gil, Jeju 63241, Korea

TEL +82-64-717-1234 FAX +82-64-717-1849 E-mail jyejye77@daum.net ORCID https://orcid.org/0000-0001-7608-0009

Copyright (c) by Korean Society for Affective Disorders. All Rights reserved.

This is an Open Access article distributed under the terms of the Creative Commons Attribution Non-Commercial License (http://creativecommons.org/licenses/ by-nc/4.0/) which permits unrestricted non-commercial use, distribution, and reproduction in any medium, provided the original work is properly cited. 
About $11.9 \%$ of college students have symptoms that fall within the category of anxiety disorder-including social anxiety disorder-which has the highest prevalence among psychiatric illnesses studied in the research targeting college students [9]. Early adulthood is an important stage of psychosocial adaptation, such as identity formation, self-directed performance, expansion of personal relationships, etc. Social anxiety symptoms of college students in this period may narrow their social network and cut opportunities for social performance, resulting in serious degradation of function and lowered quality of life [10]. Social anxiety symptoms of college students may also lead to stress and failure in social adaption [10], and may even causes or aggravate serious psychopathology, such as depression and suicide behaviors [11]. However, few studies have been conducted on the relationship between social anxiety symptoms and suicidal risk among college students. Given these, this study was performed to verify the relationship between various sociodemographic variables, social avoidance and anxiety symptoms, and suicide behaviors of college students. By doing this, the study intends to arrange a systematic intervention mechanism to manage mental health of college students to prevent them from committing suicide.

\section{MATERIALS AND METHODS}

\section{Subjects}

In this study, the researchers sent letters, including a statement explaining the purpose of the study, to colleges in the Jeju area. Two colleges agreed with the purpose of the study, and the researchers received written informed consent from 605 college students, who completed a self-administered questionnaire. Finally, 579 college students $(95.7 \%)$ were recruited for a collegebased cross-sectional survey in the Jeju area. The total sample of 579 students included 285 males (49.2\%) and 294 females (50.8\%). The mean \pm standard deviation age was $21.3 \pm 1.5$ years (males: $21.8 \pm 1.6$ years, females: $20.7 \pm 1.0$ years). This study was approved by the Institutional Review Board of Jeju National University Hospital in Korea (IRB No. JNUH 2018-10-009).

\section{Assessment}

Social anxiety symptoms was evaluated using the Korean version of the Social Avoidance Distress Scale (SADS), which is based on the SADS developed by Watson and Friend [12]; it was tested for reliability in Korean university students by Lee and Choi [13]. The SADS is a 28 -item self-report instrument. The total score ranges from 28 to 140, and higher scores indicate higher levels of social anxiety. The total score was used to determine and classify levels of social anxiety as none ( $<63$ points), mild (64-81 points), moderate (82-98 points), or severe ( $>99$ points). In the present study, those in the moderate and severe social anxiety symptom groups were considered to present higher levels of social anxiety [13].

Depressive symptoms were evaluated by the Korean version of the Center for Epidemiologic Studies Depression Scale (CES-D), which is based on the CES-D developed by Roberts et al. [14]; it was tested for validity in Korea by Cho and Kim [15]. The CES-D is a 20-item self-report instrument. The total score ranges from 0 to 60 , and higher scores indicate higher levels of depression. The optimal cut-off score identified in the validation study of the Korean version of the CES-D was 21 [15].

Suicidal risk was evaluated by the Korean version of the suicide module of the Mini International Neuropsychiatric Interview (M.I.N.I.), which is based on the suicide module of the M.I.N.I. developed by Sheehan et al. [16]; it was tested for validity in Korea by Yoo et al. [17]. The suicide module of the M.I.N.I. is a 6-item self-report instrument. The score for each answer was weighted according to its importance in assessing suicidal risk, and the total score was used to determine and classify current suicidal risk as low (1-5 points), moderate (6-9 points), or high ( $>9$ points) [17]. In the present study, those in the moderate and high risk groups were considered to present higher suicidal risk.

This study used a self-administered questionnaire to gather data on subjects' sociodemographic characteristics. The study participants completed a questionnaire regarding age, sex, family relationship, religion, history of a psychiatric disorder, history of medical illness, and socioeconomic status (SES), which was classified by family income as ' $<2$ million won per month,' ' $2-4$ million won per month,' or ' $>4$ million won per month.' 


\section{Statistical analysis}

We classified participants into four groups by the level of social anxiety and then compared the four groups according to clinical factors, including sociodemographic characteristics, depressive symptoms, and suicidal risk. Our analyses used the chi-square test for categorical variables and one-way analysis of variance for continuous variables. Scheffe's post hoc test was used to detect differences. Univariate associations between independent variables and higher levels of social anxiety were investigated. Factors potentially associated with a higher level of social anxiety in univariate analyses were entered simultaneously into a multivariate logistic regression model to assess their independence. Two-tailed pvalues of 0.05 were considered significant. All statistical analyses were conducted using IBM SPSS Statistics for Windows, Version 20.0 (IBM Co., Armonk, NY, USA).

\section{RESULTS}

According to the level of social anxiety symptoms, 579 students were classified into four groups; 169 students $(29.0 \%)$ were in the 'none' group, 249 students $(43.0 \%)$ were in the 'mild' group, 135 students $(23.3 \%)$ were in the 'moderate' group, and 27 students (4.7\%) were in the 'severe social anxiety symptoms' group. Thus, $162(28.0 \%)$ were in the 'higher level (moderate or severe) of social anxiety symptoms' group. Table 1 summarizes characteristics of the subjects by social anxiety symptom groups. A significant sex difference in group assignment was observed $(\mathrm{F}=15.65, \mathrm{p}=0.001)$; females comprised $42.9 \%$ of participants in the 'none' group, $49.0 \%$ of those in the 'mild' group, $58.5 \%$ of those in the 'moderate' group, and $77.8 \%$ of those in the 'severe social anxiety symptoms' group. No significant differences were found among the four groups in age, family relationship, religion, history of psychiatric disorder, history of medical illness, or SES.

Significant group differences were observed in CES-D total scores $(\mathrm{p}<0.001$; Table 1$)$, with mean CES-D scores of 9.5 \pm 8.4 in the 'none' group, $12.7 \pm 9.1$ in the 'mild' group, $16.5 \pm 10.4$ in the 'moderate' group, and $22.7 \pm 13.4$ in the 'severe social anxiety symptoms' group. Significant group differences were also observed in CES-D positivity (defined as total score $\geq 21$; $\mathrm{p}<0.001$; Table 1 ). CES-D positivity was $13.1 \%$ in the 'none' group, $19.3 \%$ in the 'mild' group, $34.1 \%$ in the 'moderate' group, and $51.9 \%$ in the 'severe social anxiety symptoms' group.

Significant group differences were observed in the prevalence rate for suicidal ideation within the past month ( $\mathrm{p}<0.001$; Table 2$)$, which was $11.9 \%$ in the 'none' group, $19.3 \%$ in the 'mild' group, $27.4 \%$ in the 'moderate'

Table 1. Characteristics of subjects by social anxiety symptoms

\begin{tabular}{|c|c|c|c|c|c|c|}
\hline \multirow{2}{*}{ Variable } & \multicolumn{4}{|c|}{ Social anxiety symptoms ( $n=579)$} & \multirow{2}{*}{$\chi^{2}$ or $F$} & \multirow{2}{*}{$p$-value } \\
\hline & None $(n=168)^{a}$ & Mild $(n=249)^{b}$ & Moderate $(n=135)^{c}$ & Severe $(n=27)^{d}$ & & \\
\hline Age (y) & $21.3 \pm 1.5$ & $21.2 \pm 1.4$ & $21.2 \pm 1.6$ & $21.0 \pm 1.3$ & 0.24 & 0.871 \\
\hline Sex (female) & 42.9 & 49.0 & 58.5 & 77.8 & 15.65 & $0.001 *$ \\
\hline Family income $(1,000 \mathrm{won} / \mathrm{mo})$ & & & & & 9.89 & 0.129 \\
\hline$<2,000$ & 23.2 & 20.5 & 25.9 & 11.1 & & \\
\hline $2,000 \leq$ and $<4,000$ & 52.4 & 59.4 & 45.9 & 70.4 & & \\
\hline$\geq 4,000$ & 24.4 & 25.6 & 28.1 & 18.5 & & \\
\hline Having a religion & 32.1 & 36.1 & 34.8 & 29.6 & 0.99 & 0.802 \\
\hline History of psychiatric disorder & 0.6 & 1.6 & 1.5 & 7.4 & 7.06 & 0.070 \\
\hline History of medical illness & 6.5 & 10.8 & 8.9 & 3.7 & 3.23 & 0.358 \\
\hline \multicolumn{7}{|l|}{ Depression } \\
\hline Total CES-D score & $9.5 \pm 8.4$ & $12.7 \pm 9.1$ & $16.5 \pm 10.4$ & $22.7 \pm 13.4$ & 23.47 & $\begin{array}{l}<0.001 *, \\
a<b<c<d\end{array}$ \\
\hline CES-D positivity & 13.1 & 19.3 & 34.1 & 51.9 & 33.77 & $<0.001 *$ \\
\hline
\end{tabular}

Value are presented as mean \pm standard deviation or $\%$. The chi-square test and one-way analysis of variance with post hoc test were performed to examine the difference in demographic and clinical characteristics according to social anxiety symptoms.

CES- D, the Center for Epidemiologic Studies Depression Scale.

*Statistically significant difference. 
Table 2. Comparisons and M.I.N.I. suicidal risk items by social anxiety symptoms

\begin{tabular}{|c|c|c|c|c|c|c|}
\hline & \multicolumn{4}{|c|}{ Social anxiety symptoms } & \multirow{2}{*}{$\chi^{2}$ or $\mathrm{F}$} & \multirow{2}{*}{$\mathrm{p}$-value } \\
\hline & None $(n=168)^{a}$ & Mild $(n=249)^{b}$ & Moderate $(n=135)^{c}$ & Severe $(n=27)^{d}$ & & \\
\hline Suicidal ideation, past month & 11.9 & 19.3 & 27.4 & 51.9 & 28.03 & $<0.001 *$ \\
\hline Suicidal attempt, lifetime & 1.8 & 2.4 & 3.7 & 11.1 & 7.63 & 0.054 \\
\hline M.I.N.I suicidal risk scores & $0.8 \pm 2.9$ & $1.3 \pm 3.6$ & $2.0 \pm 4.7$ & $3.4 \pm 3.9$ & 5.30 & $\begin{array}{c}0.001 * \\
a<d\end{array}$ \\
\hline
\end{tabular}

Value are presented as \% or mean \pm standard deviation. The chi-square test and one-way analysis of variance with post hoc test were performed to examine the difference in suicidal risk according to social anxiety symptoms.

M.I.N.I., Mini International Neuropsychiatric Interview.

*Statistically significant difference.

Table 3. Factors with social anxiety symptoms: multivariate analysis

\begin{tabular}{lccc}
\hline \multirow{2}{*}{ Variable } & \multicolumn{3}{c}{ Controls vs. Subjects with social anxiety symptoms } \\
\cline { 2 - 4 } & OR & $95 \% \mathrm{Cl}$ & $\mathrm{p}$-value \\
\hline Female & 1.34 & $0.92-1.95$ & 0.123 \\
CES-D positivity & 1.82 & $1.07-3.09$ & $0.026 \star$ \\
Higher suicidal risk group & 2.10 & $1.05-4.23$ & $0.037 \star$ \\
\hline
\end{tabular}

OR, odds ratio; $\mathrm{Cl}$, confidence interval; CES-D, the Center for Epidemiologic Studies Depression Scale.

*Statistically significant difference.

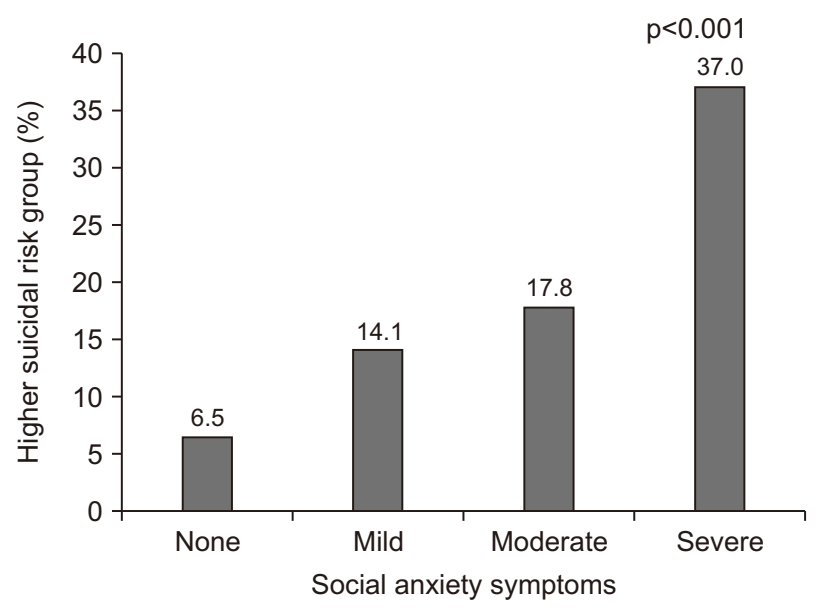

Fig. 1. Comparisons of higher suicidal risk group by social anxiety symptoms.

group, and $51.9 \%$ in the 'severe social anxiety symptoms' group. Significant group differences were also observed on the M.I.N.I. suicidal risk score ( $\mathrm{p}=0.001$; Table 2), with scores of $0.8 \pm 2.9$ in the 'none' group, $1.3 \pm 3.6$ in the 'mild' group, $2.0 \pm 4.7$ in the 'moderate' group, and $3.4 \pm 3.9$ in the 'severe social anxiety symptoms' group. Finally, significant group differences were observed in the presence of higher suicidal risk ( $p<0.001$; Fig. 1); the percentage of those with higher suicidal risk was $6.5 \%$ in the 'none' group, $14.1 \%$ in the 'mild' group, $17.8 \%$ in the 'moderate' group, and $37.0 \%$ in the 'severe social anxiety symptoms' group.

The multivariate associations between the independent factors and social anxiety symptoms are shown in Table 3. A higher level of social anxiety symptoms was significantly associated with CES-D positivity (odds ratio [OR], 1.82; 95\% confidence interval [CI], 1.07-3.09; $\mathrm{p}=0.026)$ and higher suicidal risk (OR, 2.10; CI, 1.054.23; $\mathrm{p}=0.037$ ).

\section{DISCUSSION}

In the study, it was found that $23.3 \%$ of college students had moderate social anxiety symptoms while $4.7 \%$ had severe symptoms. Comparatively few data on the prevalence of ADHD symptoms among college students is available. In a recent multi-national multi-institutional study which surveyed the annual prevalence of each mental illness, targeting adults of 18 to 22 years old including college students, it was found that the annual prevalence of phobia, including agoraphobia without medical history of panic disorder, a specific phobia, and social phobia was $9.0 \%$ for college students and $9.9 \%$ 
for adults of 18-22 year old [18]. The lifetime prevalence of social anxiety disorder drastically varies according to countries, as it was $7 \%$ to $13 \%$ in the western countries while it is $0.1 \%$ to $1.0 \%$ in Korea and other Asian countries. This is because the diagnostic threshold is higher and the perception of symptoms is lower in Asia compared to the western countries [19]. Especially, the prevalence of social anxiety disorder in Korea may be underestimated. According to the 2016 mental illnesses survey conducted in Korea, the annual prevalence of social anxiety disorder was $1.0 \%$ in the 18 to 29 yearold group and $0.1 \%$ to $0.5 \%$ in the 30 -year-old or older group. The prevalence of social anxiety symptoms in our sample was higher than the range previously reported. However, our results cannot be compared directly to those of previous studies because of differences in the instruments and diagnostic criteria used to assess social anxiety symptoms.

The results of this study show that in the group of college students, females experienced higher levels of social anxiety symptoms than males. It has been reported that females have higher prevalence of social anxiety disorder, with the male to female to ratio of $2: 3[19,20]$. In 2016, the prevalence of social anxiety disorder in Korea was $0.5 \%$ for females and $0.4 \%$ for males. The result where females showed higher prevalence is similar to this study [2]. Yonkers et al. [21] observed patients with social anxiety disorders and found that females more commonly had comorbid anxiety disorders and had more severe functional impairment than males. These sex differences are mainly influenced by learning patterns, gender roles, hormonal effects, susceptibility to stress, and differences in childhood experiences. In addition, the diversity of symptoms according to sex has a potential to affect estimation of the prevalence [22].

In this study, the group with a high level of social anxiety symptoms more responded that there were suicide behaviors for the last month, and showed higher suicidal risk. Suicidal risk factors include despair, lack of social support, psychiatric illnesses, such as anxiety disorders, mood disorders and substance use disorders, and previous suicide attempts [23]. Previous studies found that $22 \%$ of patients with social anxiety disorder experienced suicidal ideation for the last month, 35\% experienced suicide ideation throughout their lives [24-26], and 12\% to $15 \%$ of patients attempt suicide during their lifetime $[26,27]$. The suicide attempt rate of patients with social anxiety disorder in the US was three times higher than the general people [28].

This study found that social anxiety symptoms are significantly associated with depressive symptoms. Social anxiety disorder is the most common comorbid anxiety disorder among depressive patients [29,30], and comorbid social anxiety disorder diagnoses were present in $15 \%$ to $27 \%$ of patients with major depression [2931]. The comorbidity rate of major depression in social anxiety disorder is approximately $30 \%$ to $70 \%$ [30-34]. Some studies have reported that social anxiety disorder is a significant risk factor that may cause depression in all age groups $[31,33,35,36]$. In a large-scale prospective study conducted by Beesdo et al. [35], the risk of future depression in patients with social anxiety disorder was twice as high as that of those without social anxiety disorder, and was nearly three times higher than that of those without any anxiety disorders.

It is difficult to clarify the causal relationship between high suicidal risk and depressive symptoms, which were highly associated with high social anxiety level of college students. One possibility according to the interpersonal theory of suicide is that people with social anxiety symptoms feel extreme shame and thus may have a high risk of suicide in an interpersonal aspect [11]. Melancholy is also related with greater thwarted belongingness and perceived burdensomeness, which are two factors which increases risk of suicide in an interpersonal aspect [37]. In consideration of high comorbidity of depression and social anxiety disorders [36], it seems that melancholy may affect relations among suicidal risk factors regarding interpersonal relationship and social anxiety [38].

This study has the following limitations. First, this study was conducted to college students in a specific area (Jeju-si), so it is difficult to generalize the research results. Second, measures of social anxiety symptoms, suicidal behaviors and depression were based on the self-report rather than clinical evaluation. Third, as mentioned above, it is difficult to make any judgment on the causal relationship between the degree of social anxiety symptoms and related factors, due to the limitations that this study has as a cross-sectional study. Lastly, another limitation of this study is that it failed to control other factors related with social anxiety symptoms and suicidal risk, such as psychosocial stress, family environmental factors, and health-related factors. It is needed to conduct well-designed prospective studies with more variables by controlling and multiple-comparing them. 
Despite these limitations, this study has significance in that it is a study involving a large number of subjects in the local community. To our knowledge, this is the first study in Korea which investigated the relationship between social anxiety symptoms, depressive symptoms and suicide behaviors among college students.

\section{CONCLUSION}

In this study, $28.0 \%$ of college students were found to have high level of social anxiety symptoms, which was significantly associated with a higher suicidal risk. Based on these results, it may be necessary to manage and control social anxiety symptoms to prevent suicidality in Korean college students. It is important to help college students with high social anxiety symptoms in an early stage [39]. Increased awareness among parents, educators, and public health officials and a comprehensive approach to monitoring college students' mental health including their social anxiety degree are needed.

\section{CONFLICTS OF INTEREST}

The authors have nothing to disclose.

\section{ORCID}

Sang-Hun Lee
https://orcid.org/0000-0003-4410-9270
Hyun-Ju Yang
https://orcid.org/0000-0003-0027-2834
Na Ri Kang
https://orcid.org/0000-0002-2086-0927
Young-Eun Jung
https://orcid.org/0000-0001-7608-0009
Joon Hyuk Park
https://orcid.org/0000-0002-0396-5284
Moon-Doo Kim
https://orcid.org/0000-0002-6441-630X
Young-Sook Kwak
https://orcid.org/0000-0002-6071-238X

\section{REFERENCES}

1. Kessler RC, Petukhova M, Sampson NA, Zaslavsky AM, Wittchen HU. Twelve-month and lifetime prevalence and lifetime morbid risk of anxiety and mood disorders in the United States. Int J Methods Psychiatr Res 2012;21:169-84.

2. Ministry of Health and Welfare, Samsung Medical Center. The survey of mental disorders in Korea, 2016. Ministry of Health and Welfare; 2017.

3. Furmark T. Social phobia: overview of community surveys. Acta Psychiatr Scand 2002;105:84-93.

4. Schneier FR. Social anxiety disorder. N Engl J Med 2006;355:1029-36.

5. Ruscio AM, Brown TA, Chiu WT, Sareen J, Stein MB, Kessler RC. Social fears and social phobia in the USA: results from the National Comorbidity Survey Replication. Psychol Med 2008;38:15-28.

6. Schneier FR, Johnson J, Hornig CD, Liebowitz MR, Weissman MM. Social phobia. Comorbidity and morbidity in an epidemiologic sample. Arch Gen Psychiatry 1992;49:2828.

7. Statistics Korea. Annual report on the cause of death statistics [Internet]. Daejeon: Statistics Korea; 2017 [cited 2018 Sep 19]. Available from: http://kostat.go.kr/portal/korea/ kor_nw/1/6/1/index.board?bmode=read\&aSeq=370710.

8. Sher L, Oquendo MA, Mann JJ. Risk of suicide in mood disorders. Clin Neurosci Res 2001;1:337-44.

9. Blanco C, Okuda M, Wright C, Hasin DS, Grant BF, Liu $\mathrm{SM}$, et al. Mental health of college students and their noncollege-attending peers: results from the National Epidemiologic Study on Alcohol and Related Conditions. Arch Gen Psychiatry 2008;65:1429-37.

10. Kessler RC. The impairments caused by social phobia in the general population: implications for intervention. Acta Psychiatr Scand Suppl 2003;(417):19-27.

11. Arditte KA, Morabito DM, Shaw AM, Timpano KR. Interpersonal risk for suicide in social anxiety: the roles of shame and depression. Psychiatry Res 2016;239:139-44.

12. Watson D, Friend R. Measurement of social-evaluative anxiety. J Consult Clin Psychol 1969;33:448-57.

13. Lee JY, Choi CH. A study of the reliability and the validity of the Korean versions of social phobia scales (K-SAD, KFNE). Korean J Clin Psychol 1997;16:251-64.

14. Roberts RE, Rhoades HM, Vernon SW. Using the CES-D scale to screen for depression and anxiety: effects of language and ethnic status. Psychiatry Res 1990;31:69-83.

15. Cho MJ, Kim KH. Use of the Center for Epidemiologic Studies Depression (CES-D) Scale in Korea. J Nerv Ment Dis 1998;186:304-10.

16. Sheehan DV, Lecrubier Y, Sheehan KH, Amorim P, Janavs J, Weiller E, et al. The Mini-International Neuropsychiatric Interview (M.I.N.I.): the development and validation of a structured diagnostic psychiatric interview for DSM-IV and ICD-10. J Clin Psychiatry 1998;59 Suppl 20:22-33. 
17. Yoo SW, Kim SY, Noh JS, Oh KS, Kim CH, Namkoong K, et al. Validity of Korean version of the mini-international neuropsychiatric interview. Anxiety Mood 2006;2:50-5.

18. Auerbach RP, Alonso J, Axinn WG, Cuijpers P, Ebert DD, Green JG, et al. Mental disorders among college students in the World Health Organization World Mental Health Surveys. Psychol Med 2016;46:2955-70.

19. Rapee RM, Spence SH. The etiology of social phobia: empirical evidence and an initial model. Clin Psychol Rev 2004;24:737-67.

20. Hidalgo RB, Barnett SD, Davidson JR. Social anxiety disorder in review: two decades of progress. Int J Neuropsychopharmacol 2001;4:279-98.

21. Yonkers KA, Dyck IR, Keller MB. An eight-year longitudinal comparison of clinical course and characteristics of social phobia among men and women. Psychiatr Serv 2001;52:637-43.

22. Xu Y, Schneier F, Heimberg RG, Princisvalle K, Liebowitz MR, Wang S, et al. Gender differences in social anxiety disorder: results from the national epidemiologic sample on alcohol and related conditions. J Anxiety Disord 2012;26:129.

23. Arria AM, O'Grady KE, Caldeira KM, Vincent KB, Wilcox HC, Wish ED. Suicide ideation among college students: a multivariate analysis. Arch Suicide Res 2009;13:230-46.

24. Cox BJ, Direnfeld DM, Swinson RP, Norton GR. Suicidal ideation and suicide attempts in panic disorder and social phobia. Am J Psychiatry 1994;151:882-7.

25. Olfson M, Guardino M, Struening E, Schneier FR, Hellman F, Klein DF. Barriers to the treatment of social anxiety. Am J Psychiatry 2000;157:521-7.

26. Thibodeau MA, Welch PG, Sareen J, Asmundson GJ. Anxiety disorders are independently associated with suicide ideation and attempts: propensity score matching in two epidemiological samples. Depress Anxiety 2013;30:947-54.

27. Cougle JR, Keough ME, Riccardi CJ, Sachs-Ericsson N. Anxiety disorders and suicidality in the National Comorbidity Survey-Replication. J Psychiatr Res 2009;43:825-9.

28. Kessler RC, Borges G, Walters EE. Prevalence of and risk factors for lifetime suicide attempts in the National Comorbidity Survey. Arch Gen Psychiatry 1999;56:617-26.
29. Belzer K, Schneier FR. Comorbidity of anxiety and depressive disorders: issues in conceptualization, assessment, and treatment. J Psychiatr Pract 2004;10:296-306.

30. Kessler RC, Stang P, Wittchen HU, Stein M, Walters EE. Lifetime co-morbidities between social phobia and mood disorders in the US National Comorbidity Survey. Psychol Med 1999;29:555-67.

31. Fava M, Rankin MA, Wright EC, Alpert JE, Nierenberg AA, Pava J, et al. Anxiety disorders in major depression. Compr Psychiatry 2000;41:97-102.

32. Dalrymple KL, Zimmerman M. Does comorbid Social Anxiety Disorder impact the clinical presentation of principal Major Depressive Disorder? J Affect Disord 2007;100:2417.

33. Stein MB, Tancer ME, Gelernter CS, Vittone BJ, Uhde TW. Major depression in patients with social phobia. Am J Psychiatry 1990;147:637-9.

34. Van Ameringen M, Mancini C, Styan G, Donison D. Relationship of social phobia with other psychiatric illness. J Affect Disord 1991;21:93-9.

35. Beesdo K, Bittner A, Pine DS, Stein MB, Höfler M, Lieb R, et al. Incidence of social anxiety disorder and the consistent risk for secondary depression in the first three decades of life. Arch Gen Psychiatry 2007;64:903-12.

36. Ohayon MM, Schatzberg AF. Social phobia and depression: prevalence and comorbidity. J Psychosom Res 2010;68:235-43.

37. Silva C, Ribeiro JD, Joiner TE. Mental disorders and thwarted belongingness, perceived burdensomeness, and acquired capability for suicide. Psychiatry Res 2015;226:31627.

38. Davidson CL, Wingate LR, Grant DM, Judah MR, Mills AC. Interpersonal suicide risk and ideation: the influence of depression and social anxiety. J Soc Clin Psychol 2011;30:842-55.

39. Harrod CS, Goss CW, Stallones L, DiGuiseppi C. Interventions for primary prevention of suicide in university and other post-secondary educational settings [Internet]. USA: Cochrane Database Syst Rev; 2014 [cited 2014 Oct 29]. Available from: https://www.cochranelibrary.com 